\title{
Development and comparison of cell-free protein synthesis systems derived from typical bacterial chassis
}

\author{
Liyuan Zhang ${ }^{1,2 \dagger}$, Xiaomei Lin ${ }^{2 \dagger}$, Ting Wang ${ }^{2 \dagger}$, Wei Guo ${ }^{1 *}$ and Yuan Lu $^{2 *}$ (1)
}

\begin{abstract}
Cell-free protein synthesis (CFPS) systems have become an ideal choice for pathway prototyping, protein production, and biosensing, due to their high controllability, tolerance, stability, and ability to produce proteins in a short time. At present, the widely used CFPS systems are mainly based on Escherichia coli strain. Bacillus subtilis, Corynebacterium glutamate, and Vibrio natriegens are potential chassis cells for many biotechnological applications with their respective characteristics. Therefore, to expand the platform of the CFPS systems and options for protein production, four prokaryotes, E. coli, B. subtilis, C. glutamate, and V. natriegens were selected as host organisms to construct the CFPS systems and be compared. Moreover, the process parameters of the CFPS system were optimized, including the codon usage, plasmid synthesis competent cell selection, plasmid concentration, ribosomal binding site (RBS), and CFPS system reagent components. By optimizing and comparing the main influencing factors of different CFPS systems, the systems can be optimized directly for the most influential factors to further improve the protein yield of the systems. In addition, to demonstrate the applicability of the CFPS systems, it was proved that the four CFPS systems all had the potential to produce therapeutic proteins, and they could produce the receptor-binding domain (RBD) protein of SARS-CoV-2 with functional activity. They not only could expand the potential options for in vitro protein production, but also could increase the application range of the system by expanding the cell-free protein synthesis platform.
\end{abstract}

Keywords: Escherichia coli, Bacillus subtilis, Corynebacterium glutamate, Vibrio natriegens, Cell-free protein synthesis system, SARS-CoV-2 RBD protein expression

\section{Introduction}

Cell-free protein synthesis (CFPS) is a way for rapid protein synthesis in vitro (Carlson et al. 2012; Gregorio et al. 2019). Extract-based CFPS systems as tools have promoted the development of basic biology and applied biology. They provide some unique advantages for the production and application of proteins. For example,

\footnotetext{
*Correspondence: 1999500011@syau.edu.cn; yuanlu@tsinghua.edu.cn †Liyuan Zhang, Xiaomei Lin and Ting Wang contributed equally to this work

1 Department of Ecology, Shenyang Agricultural University, Shenyang 110866, Liaoning Province, China

${ }^{2}$ Key Laboratory of Industrial Biocatalysis, Ministry of Education, Department of Chemical Engineering, Tsinghua University, Beijing 100084, China
}

the open environment of the reaction allows users to directly add or synthesize new ingredients at precise concentrations, allowing them to be designed, tested and optimized for different products in a faster, more convenient, and more controlled manner (Sullivan et al. 2016). Higher tolerance facilitates the production of toxic protein products. In addition, CFPS systems can be stored in lyophilized form for up to 1 year, demonstrating greater stability (Smith et al. 2014). These advantages make the CFPS systems an ideal choice for path design, protein production, and personalized medicine (Hodgman and Jewett 2012; Kelwick et al. 2014; Lu 2017). Therefore, they are increasingly used in the production of complex protein products with low expression rates, aggregation, toxicity, and poor solubility in vivo (Schoborg et al. 2018). 
CFPS systems also have broad application prospects and have been used in the design of rapid prototyping of DNA regulatory elements, logic systems (Chappell et al. 2013; Karim and Jewett 2016; Stech and Kubick 2015), and biosensor devices (Lin et al. 2020a, b; Pardee et al. 2016; Zhang et al. 2020, 2019).

In recent years, taking advantage of the diversity of cell biosynthesis has led to an increase in the number of host species used for different CFPS systems (Zemella et al. 2015). In theory, any organism could be used as a basis for CFPS. CFPS systems are mainly divided into eukaryotic and prokaryotic systems. Yeast, wheat germ, rabbit reticulocyte and insect cell are commonly used as eukaryotic hosts for cell-free systems. Eukaryotic cells, as safe host cells, have complex post-translational modification functions and can produce more complex proteins. However, the high cost of cultivating eukaryotic cells, the more complex process, and the low protein yield in batch reaction make people more inclined to study the CFPS system of prokaryotic host cells (Adiga et al. 2018). Compared with the eukaryotic system, the prokaryotic system has more convenient extraction solution preparation, higher protein yield, lower downstream processing requirements, and lower cost. At present, Escherichia coli is the most popular and widely used prokaryotic CFPS system (Failmezger et al. 2017). In addition, cell-free systems of prokaryotic hosts with different model strains such as Vibrio (Des Soye et al. 2018; Li et al. 2017; Moore et al. 2017; Wiegand et al. 2018), Pseudomonas (Wang et al. 2018) and Bacillus (Kelwick et al. 2016; Moore et al. 2018) have also begun to develop in recent years. However, these studies only established relevant systems, but they lacked comparative analysis among different CFPS systems. Therefore, in-depth exploration and comparative analysis should be carried out so as to guide the application of the systems better.

The development of CFPS needs to focus on common and valuable chassis cells, such as Escherichia coli, Bacillus subtilis, Corynebacterium glutamicum and Vibrio natriegens. E. coli, B. subtilis, C. glutamicum and V. natriegens are reliable and powerful base microorganisms for laboratory research and industrial production. They have different characteristics and can be the focus of the CFPS platform. E. coli, as the preferred host cell for the present CFPS systems, has obvious advantages, such as the simple operation of culture conditions and cell lysis methods, the maximum protein yield with several milligrams $/ \mathrm{ml}$, and the low cost of cell culture (Failmezger et al. 2017). B. subtilis has no obvious codon preference, can avoid codon optimization, and is widely used in industrial protein production (Guan et al. 2016; Jeong et al. 2014; Sarah et al. 2016). C. glutamicum has minimal protease activity, which gives this strain a strong potential to express protease-sensitive proteins (Smith et al. 2010; Sun et al. 2016). In addition, both B. subtilis and C. glutamicum belong to Gram-positive strains and are nonpathogenic microorganisms with less endotoxicity, so they can be safely used in the production of food and pharmaceutical proteins. The doubling time of $V$. natriegens is twice as fast as that of E. coli, and it produces a large number of ribosomes that support its robust transcription system of rapid growth, giving $V$. natriegens the potential to achieve excellent productivity in the field of high levels of protein expression (Becker et al. 2019; Dalia et al. 2017; Des Soye et al. 2018; Fernández-Llamosas et al. 2017; Tschirhart et al. 2019; Weinstock et al. 2016; Wiegand et al. 2018). The foregoing features give people new interest in the development and use of CFPS systems based on these strains. Among them, the CFPS systems of $E$. coli are more comprehensive. These cell-free systems have been continuously improved and optimized through various researches, resulting in a high-yield system, and a wide range of applications, including the production of applied proteins and commercial small molecule products, and the design of cell-free biosensors. However, there are few relevant studies on the three CFPS systems of B. subtilis, C. glutamicum and $V$. natriegens. These three systems should be further studied and optimized, and different CFPS systems should be compared and analyzed. In this way, the advantages and important influencing factors of different systems can be obtained. Through targeted optimization, the efficiency and expression level of the system can be improved to assist further application to select a more effective CFPS system.

Here, this study aims to build a robust and productive CFPS platform based on E. coli, B. subtilis, C. glutamicum and $V$. natriegens (Fig. 1). Then the protein synthesis yield of these systems was improved by systematically optimizing the process parameters. Specifically, the effects of DNA template (including codons, competent cells used for plasmid extraction, plasmid concentration, and RBS) and system reagent components (including $\mathrm{Mg}^{2+}$, PEP, NTPs, amino acids, oxidized reductant, and PEG8000) on sfGFP (superfolder green fluorescent protein) synthesis yield were evaluated. Furthermore, the differences and main influencing factors of different CFPS systems were compared and analyzed. Then, to demonstrate the applicability of the CFPS systems, the four CFPS systems were used to express the therapeutic SARS-CoV-2 RBD protein and to examine its activity characterization. It is hoped that by developing the CFPS system in different host cells, the platform range and potential options for in vitro protein production can be expanded, and a variety of highly expressed structural and functional proteins 


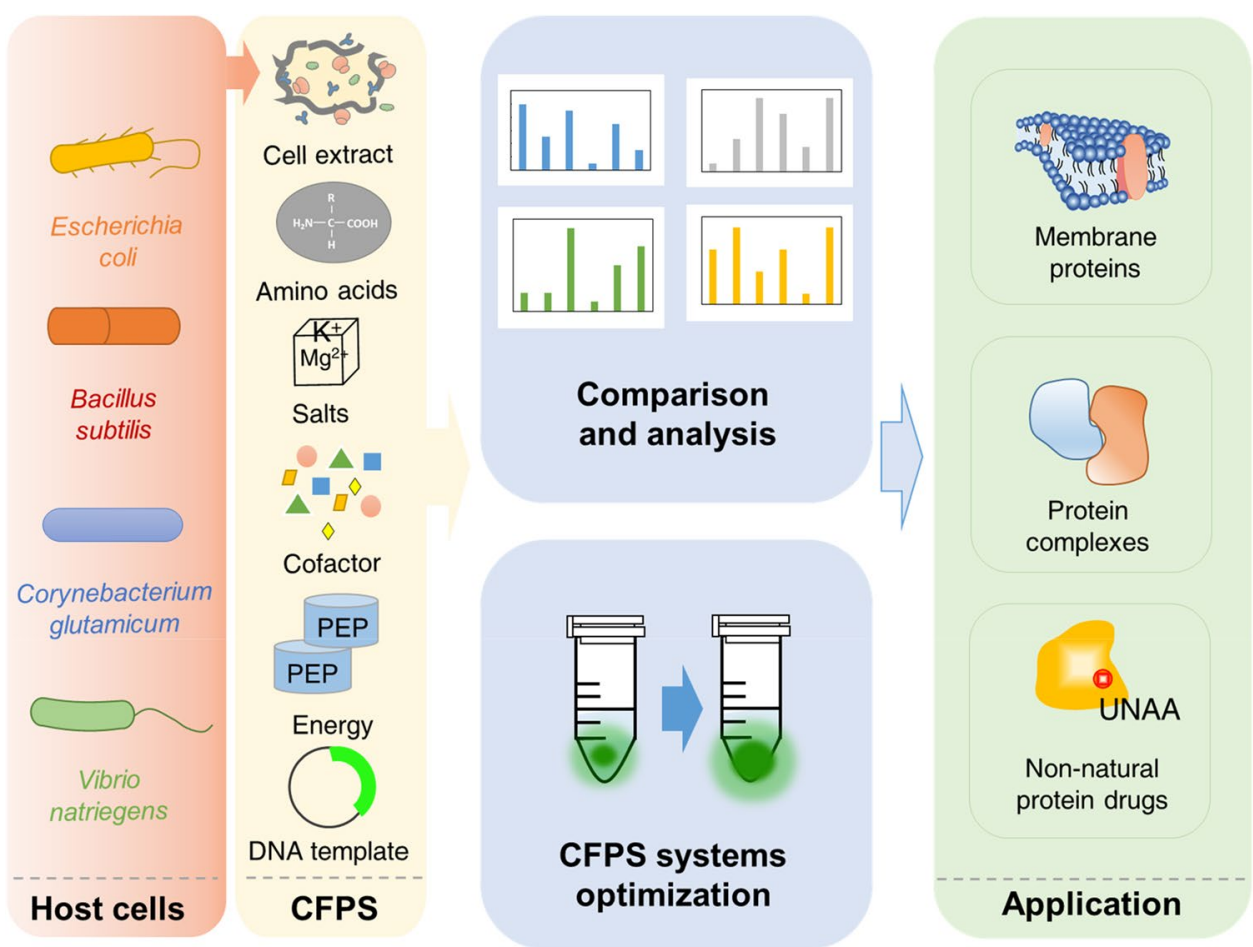

Fig. 1 The CFPS system as a platform for basic scientific research, preliminary screening and related applications

can be produced for applications in pharmaceutical proteins and other fields.

\section{Results and discussion}

\section{Codon optimization}

Every organism used for protein expression exhibits some degree of difference or preference in codon utilization. To make use of preferred codons, avoid low-utilization or rare codons, and enable the protein production system to carry out high level expression, the codons of B. subtilis, C. glutamicum and $V$. natriegens plasmids were optimized. Codon optimization for B. subtilis, C. glutamicum and $V$. natriegens plasmids was based on $E$. coli plasmids. According to the experimental data (Fig. 2), the protein synthesis level of the B. subtilis and $V$. natriegens CFPS systems was only slightly increased after codon optimization. The codon optimization had no significant effect on the protein synthesis of these systems, possibly because the bacteria itself had no obvious codon preference. However, for C. glutamate CFPS system, codon optimization could significantly increase the protein synthesis level of the system by nearly $30-40 \%$. Therefore, when $B$. subtilis system and $V$. natriegens system were used for the expression of functional proteins in the future, the step of codon optimization could be omitted. In the C. glutamicum system, the protein expression could be improved through the codon optimization. In addition, from the protein synthesis level of these systems, the initial protein synthesis level of the B. subtilis, C. glutamicum and $V$. natriegens CFPS systems were much lower than that of the E. coli CFPS system.

Optimization of plasmid source and plasmid concentration To explore the optimal conditions of target gene expression and obtain higher protein expression level, different plasmid sources were used to test their influences on protein expression. Plasmid transcription is influenced by host background and regulated by host factors. The difference in host background can affect the transcription mode of plasmid skeleton and auxiliary genes (Carroll and Wong 2018; Miyakoshi et al. 2009). The restrictive modification systems of the host can recognize and destroy exogenous DNA. For example, methylation of $\mathrm{Dam}^{+}$and $\mathrm{Dcm}^{+}$interferes with the cleavage of DNA cloned and propagated in E. coli strains, and also affects the efficiency of plasmid transformation (Russell and Zinder 1987). In addition, the host recombination system can catalyze the rearrangement of recombinant molecules, affecting the integrity of DNA (Weinstock et al. 2016). Certain genes in the host (e.g., Lon) encode specific proteases that cause degradation of the recombinant protein, reducing protein production (Phillips 


\section{a DNA}

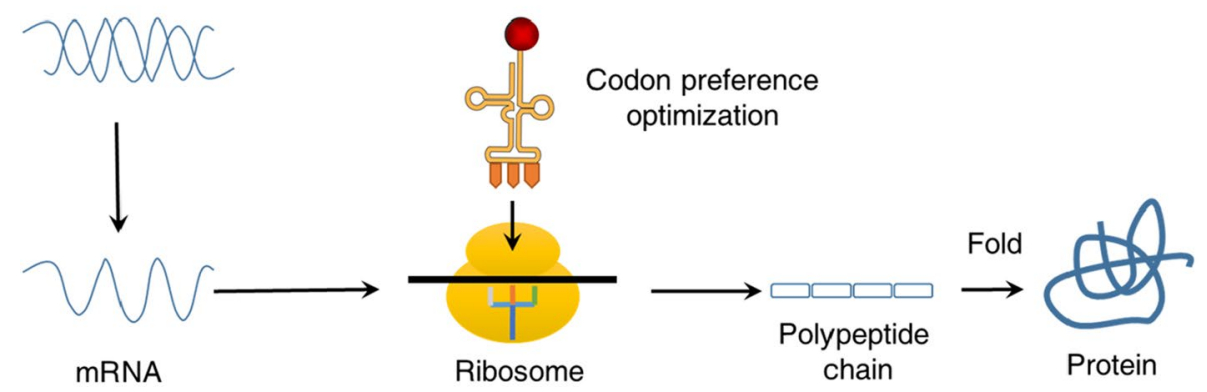

b

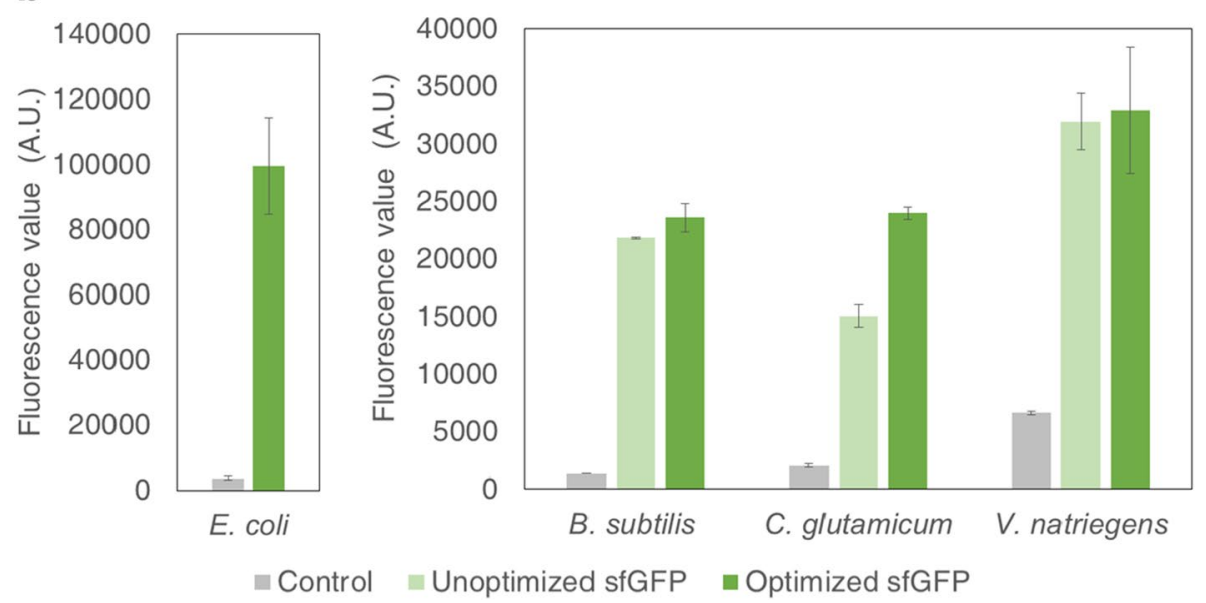

Fig. 2 Effect of codon optimization on protein expression of E. coli, B. subtilis, C. glutamicum and V. natriegens CFPS systems. a Diagram of protein expression process. b sfGFP protein synthesis level after codon optimization of E. coli, B. subtilis, C. glutamicum and V. natriegens CFPS systems. The mean and standard deviations are shown $(\mathrm{N}=3)$. (The control is the background value of the systems.)

et al. 1984). As host cells might affect the transcription functions of plasmids, seven common E. coli competent cells (JM110, JM109, DH10B, DH5 $\alpha$, TOP10, Turbo, XL1-Blue) were selected for testing (Casali 2003). The data (Fig. 3) showed that the selection of competent cells had a significant effect on the protein yield of the system, with a nearly twofold difference in the yield between different competent cells. The optimal competent cell of $E$. coli system was DH5 $\alpha$, and the less effective competent cells were DH10B and TOP10 (Fig. 3a). The experimental data showed that for the B. subtilis, C. glutamicum and $V$. natriegens CFPS systems, the sfGFP expression reached a peak when XL1-Blue competent cell was used, and the use of DH5 $\alpha$ competent cell resulted in low expression (Fig. 3bcd). These results indicated that $\mathrm{DH} 5 \alpha$ was more suitable as a source of plasmids in E. coli system, which was conducive to protein expression. Moreover, the plasmids obtained from XL1-Blue were more suitable for the expression of B. subtilis, C. glutamicum and V. natriegens system proteins.
In addition, DNA concentration is the critical factor affecting the protein yield in CFPS reactions. Therefore, the next step was attempted to optimize protein expression by adjusting the plasmid concentration in cell-free reactions. It is hypothesized that an increase in plasmid concentration could lead to an increase in protein production. By increasing the plasmid concentration from $0 \mathrm{ng} / \mu \mathrm{L}$ to $1200 \mathrm{ng} / \mu \mathrm{L}$ (the range set by the pre-experiment), it was observed that there was a saturation point of plasmid concentration. The protein yield increased with the increase of plasmid concentration before reaching saturation point and tended to be stable after reaching the saturation point. From $100 \mathrm{ng} / \mu \mathrm{L}$ to the optimal plasmid concentration, protein yield could be increased by about 1-3 times (Fig. 3). Finally, the experimental data showed that for the $E$. coli CFPS system, the sfGFP expression reached a peak when $300 \mathrm{ng} / \mu \mathrm{L}$ plasmid DNA was provided as the template (Fig. 3a). The optimal plasmid concentration of B. subtilis system was $700 \mathrm{ng} /$ $\mu \mathrm{L}$ (Fig. 3b). For the C. glutamicum CFPS system, the 
a

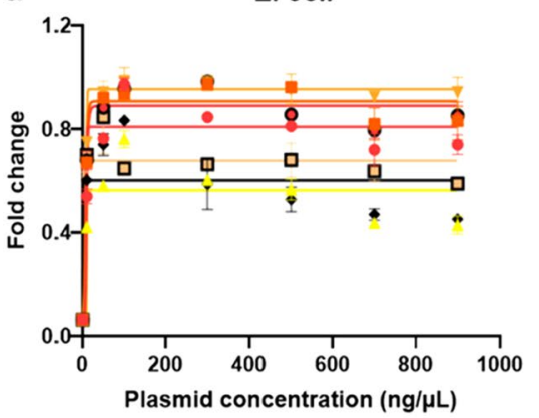

C

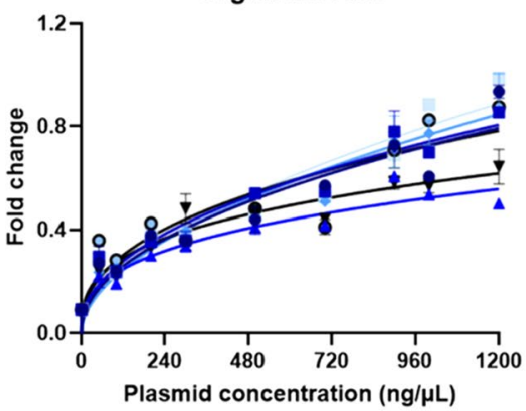

b
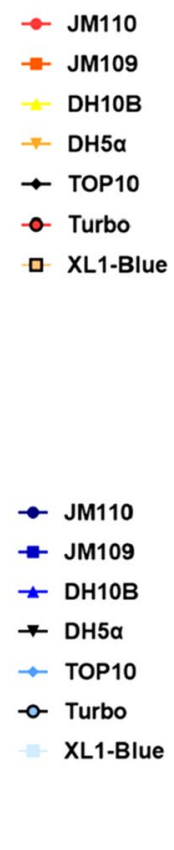

d
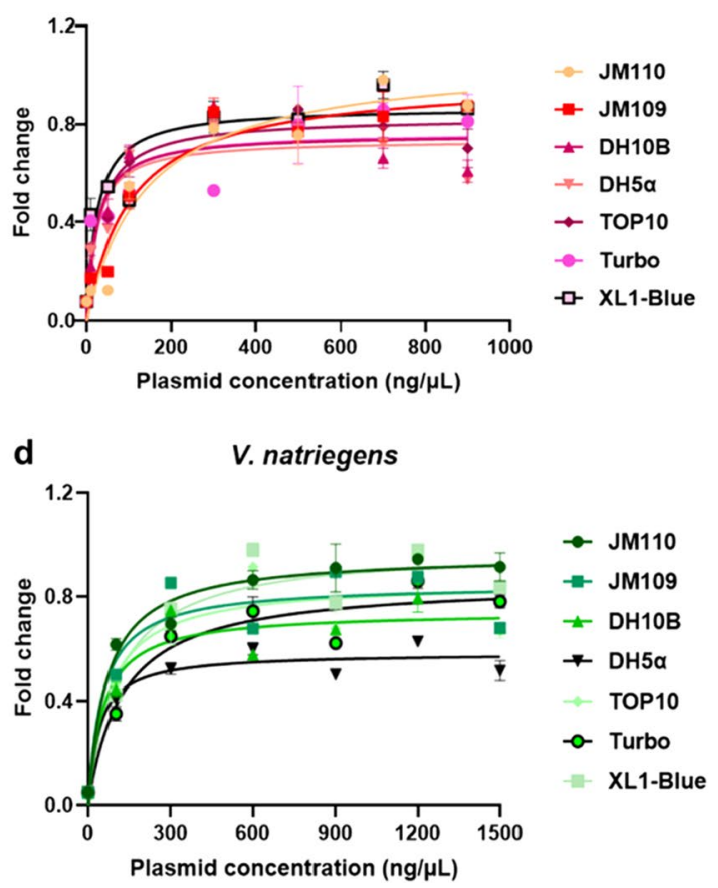

Fig. 3 Screening of competent cells and DNA concentrations in E. coli, B. subtilis, C. glutamate and V. natriegens CFPS systems. a E. coli CFPS system. b $B$. subtilis CFPS system. c C. glutamicum CFPS system. $\mathbf{d}$ V. natriegens CFPS system. The data were normalized. The mean and standard deviations are shown $(\mathrm{N}=3)$. The number "1" of the normalized treatment represented the optimal fluorescence value of each factor in each CFPS system

expression level of sfGFP was always on the rise in the selected plasmid concentration range, so the maximum value of the selected range was $1200 \mathrm{ng} / \mu \mathrm{L}$ (Fig. 3c). For the $V$. natriegens CFPS system, the sfGFP expression reached the peak when the $600 \mathrm{ng} / \mu \mathrm{L}$ plasmid DNA was provided as the template (Fig. 3d). However, the optimal plasmid concentrations required by B. subtilis, C. glutamicum and $V$. natriegens systems were all higher than those of E. coli systems, indicating that these three systems required more transcription elements to support the transcription and translation processes. The reason also could be that the transcription and the translation were inefficient, or the RNAs were easily degraded. In the future, to decrease the plasmid usage of these three systems, the genomes of the three model cells could be modified to enhance the transcription and translation process.

\section{The influence of RBS on different CFPS systems}

It has been reported that there are significant differences in the initial translation efficiency and protein expression levels, with different intensities of RBS (ribosomal binding site) sequences (Shi et al. 2018). For this test, six RBS sequences were selected for each CFPS system to test the relationship between RBS and sfGFP yield.
RBS sequences were designed according to RBS Library Calculator (Li et al. 2016; Salis 2011), and the six RBS sequences (Table 1 ) were equably selected from the minimum to the maximum translation initiation rates (see "Materials and methods" for detailed information). The fluorescence intensity of the system was quantified to screen RBS with different theoretical translation initiation rates, and finally, the influence of the designed RBS on the protein expression of the systems was obtained.

Theoretically, with the increase of the initial translation rate, the synthesis efficiency of sfGFP protein should be better, and the protein synthesis level of the system should be higher. However, the results were not regular, the protein synthesis level did not increase with the increase of the initial rate of RBS translation, and did not show a linear trend. As shown by the normalized experimental results, the new RBS designed for E. coli CFPS system (Fig. 4a) were all successfully expressed, but overall, most of the newly designed RBS did not have higher protein synthesis level than the original RBS, and only the protein synthesis level of RBS3 was slightly higher than the original RBS (RBS0). For the B. subtilis cellfree system (Fig. 4b), where none of the newly designed RBS sequences were successfully expressed. In addition, only RBS3 and RBS6 were successfully expressed in the 
Table 1 RBS sequences designed by RBS Library Calculator

\begin{tabular}{|c|c|c|c|}
\hline Bacterial specie & RBS number & RBS sequence & $\begin{array}{l}\text { Translation } \\
\text { initiation rate }\end{array}$ \\
\hline \multirow[t]{7}{*}{ E. coli } & Original & GAAGGAG & 6748.38 \\
\hline & 1 & CCCGAUGGGAUCACGCAUCUAAGG & 0.13 \\
\hline & 2 & UCCGAUGCGACAAGGCAGGUCCUA & 9.43 \\
\hline & 3 & UCCGAUGGGACAAGGCAGAUCCUA & 38.37 \\
\hline & 4 & CCCGAUGCGAUCAAGGAUCUAAGG & 158.33 \\
\hline & 5 & CCCGAUGGGAUCAAGAAUGUAAGG & 642.63 \\
\hline & 6 & UCCGAUGGGACAAAGGAGGUUGUA & $67,421.00$ \\
\hline \multirow[t]{7}{*}{ B. subtilis } & Original & GAAGGAG & 9491.88 \\
\hline & 1 & UUAUAGACAUUGGACAGUUCCUCGUUA & 0.35 \\
\hline & 2 & UUAUAGACAUUGGGAAGUUCCUCCUUA & 32.55 \\
\hline & 3 & UUAUAGACAUUGGAAAGUUACUCCUUA & 130.15 \\
\hline & 4 & 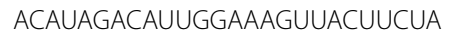 & 464.48 \\
\hline & 5 & ACGAUGUAGUGAAGGGGUUACUUAUA & 2053.54 \\
\hline & 6 & ACAAUGUAGUGAAGGGGGUACUUAUU & $189,477.64$ \\
\hline \multirow[t]{7}{*}{ C. glutamicum } & Original & GAAGGAG & 8338.00 \\
\hline & 1 & UUCGGUUUACUAAACGCGCCCUUAU & 0.12 \\
\hline & 2 & UGCGGUUUACUAAACGGACCCUUAU & 8.12 \\
\hline & 3 & UGCGGUUUACUAAAAGCACCCAUAU & 32.02 \\
\hline & 4 & UUCAGUUGGUAAAGGGAACCCAUAU & 95.11 \\
\hline & 5 & GUCAGAUGGUAAAAAGGAGUUAAUCC & 416.15 \\
\hline & 6 & UAAUAGUCACUUUAAGGAGGUUUAU & $50,737.39$ \\
\hline \multirow[t]{7}{*}{ V. natriegens } & Original & GAAGGAG & 6748.83 \\
\hline & 1 & CCGUAUUUUUUCGACGCCGGUAUCCU & 0.15 \\
\hline & 2 & CAGUCUUUUUUCAGCGCAGGUAAACA & 12.18 \\
\hline & 3 & CCGUAUUUUUUCAAGGCCGGUAACAU & 50.95 \\
\hline & 4 & CCGUAUUUUUUCAAUGGCGGUAAUAU & 201.77 \\
\hline & 5 & CCGUAUUUUUUCUACGGAGGUAUUCU & 1184.25 \\
\hline & 6 & CCGUAUUUUUUCAAGGGAGGUUAUAU & $31,367.00$ \\
\hline
\end{tabular}

C. glutamicum system (Fig. 4c), and the protein synthesis level of RBS3 was $40 \%$ higher than that of the original RBS0. For the $V$. natriegens system (Fig. 4d), none of RBS1-5 made protein expression. Although RBS6 made protein successfully expressed, it was still not as high as the protein synthesis level of the original RBS0. This indicated that there was a gap between the results predicted by the experimental theory and the test results. However, the theoretical prediction provided a certain reference for this experiment and helped to carry out the test.

Some of the designed RBS were not expressed probably due to the following reasons. First, the computer simulation itself had errors in predicting the RBSs. Second, the computer-designed RBS sequences for suitable hosts were more suitable for cells study. Third, the systems were not expressed well and did not present the expected results because the RBSs designed with a suitable host were not adapted to the promoter, vector or plasmid source. However, the results also showed that the CFPS system could provide a very fast method for screening and testing libraries. Therefore, the specific impact of RBSs on CFPS systems still needs further study.

\section{Optimization of cell-free system reagent components}

The next study was to optimize reagent components of the CFPS system. The extract-based CFPS system utilizes some essential substrates (including amino acids, energy substrates, cofactors, and salts) that are essential for protein synthesis from CFPS systems (Carlson et al. 2012). All these components affect protein synthesis to a certain extent. E. coli, B. subtilis, C. glutamate and $V$. natriegens CFPS systems may have different requirements for small molecules and other reagents. Therefore, the effects of several important system parameters $\left(\mathrm{Mg}^{2+}\right.$, PEP, NTPs, amino acids, oxidized reductant and PEG8000) on the yield of sfGFP in different CFPS systems were explored (Fig. 5a) (Des Soye et al. 2018). It is hypothesized that by modifying the $E$. coli CFPS system 
a
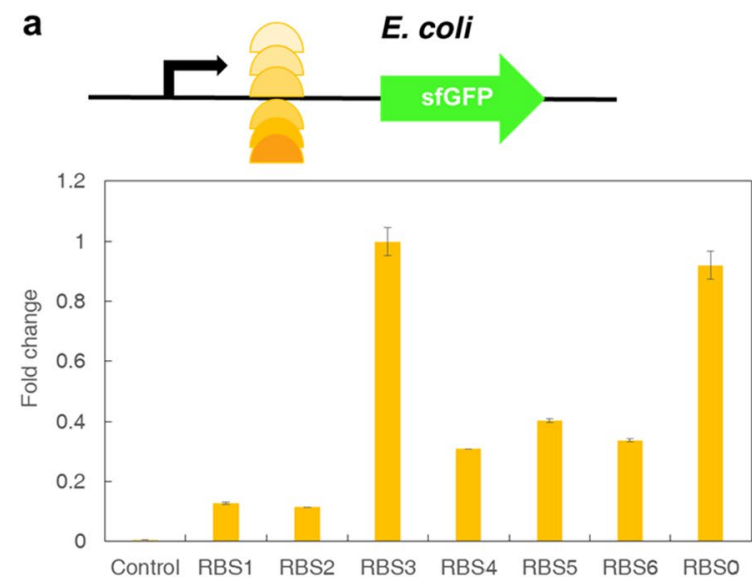

c
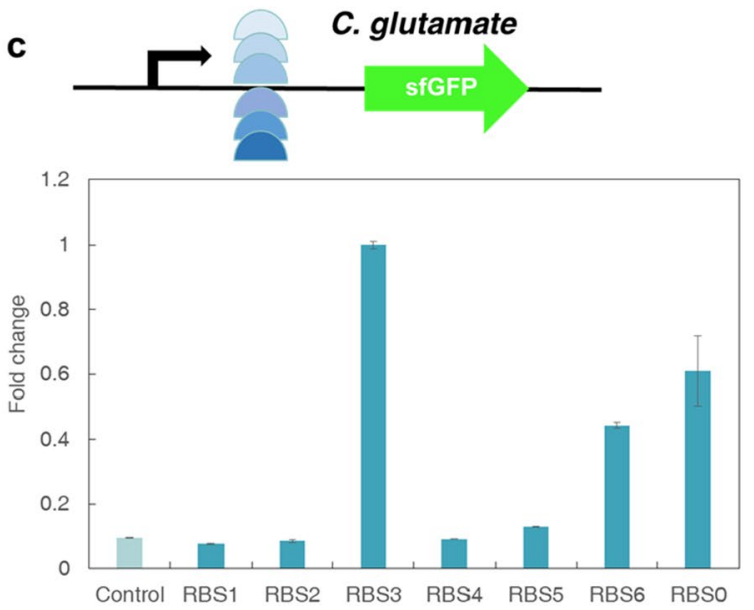

b
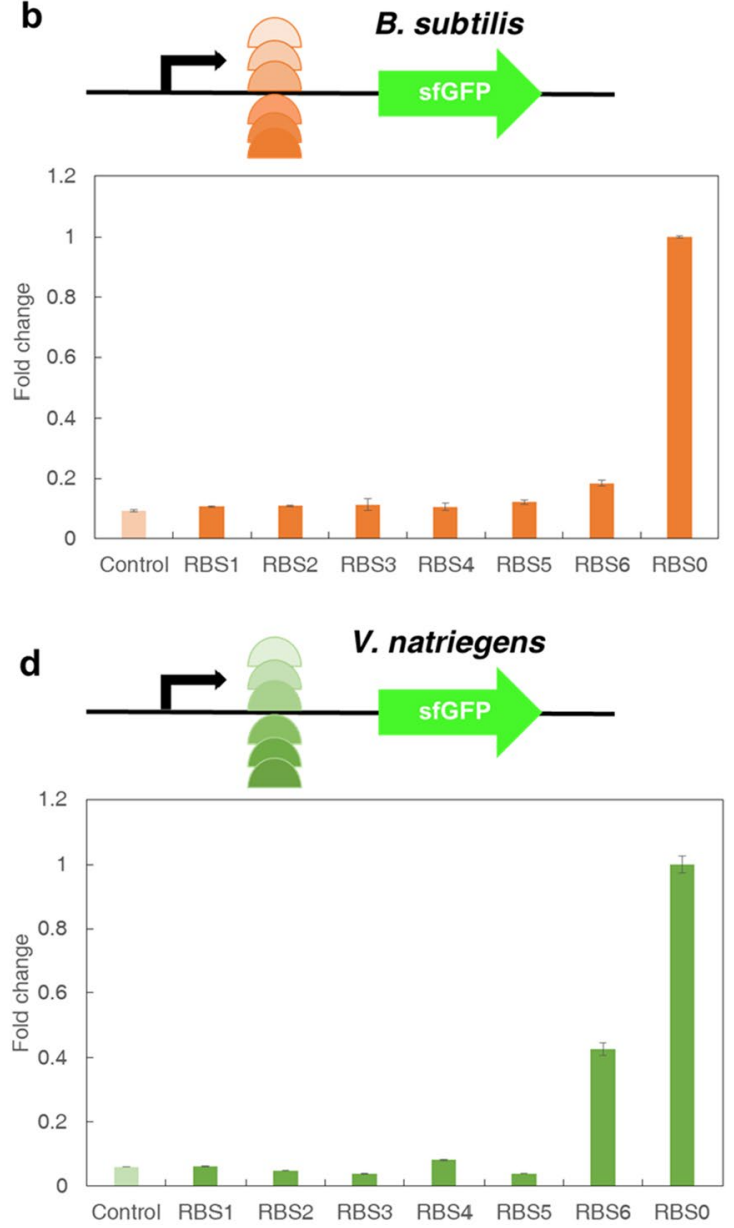

Fig. 4 Effect of RBS on protein expression in E. coli, B. subtilis, C. glutamate and V. natriegens CFPS systems. a E. coli CFPS system. b B. subtilis CFPS system. c C. glutamate CFPS system. d V. natriegens CFPS system. The control is the background value of the systems, and the mean and standard deviations are shown $(\mathrm{N}=3)$. The number "1" of the normalized treatment represented the optimal fluorescence value of each factor in each CFPS system

components of known protocol (Jiang et al. 2021) and conducting new experiments on different systems, the optimal system components suitable for different CFPS systems was obtained. A uniform gradient was designed (Additional file 1: Table S2) by varying the concentrations of several key components according to the known component combination. According to the gradient experiment, the optimal number of different components was selected. Meanwhile, the concentration of all other components in CFPS remained constant during the optimization process.

The effect of magnesium ions $\left(\mathrm{Mg}^{2+}\right)$ on protein expression in different CFPS systems was first studied. $\mathrm{Mg}^{2+}$ can be used to balance the charges generated by nucleic acid phosphate groups and other anionic species in the system. It can also affect the interactions between proteins and nucleic acids in biological processes such as protein synthesis, and can act as an activator of some enzymes (RNA polymerase and carbamyl tRNA synthase) (Jiang, et al. 2021; Levine et al. 2019). It was found that the concentration of $\mathrm{Mg}^{2+}$ had a great influence on the expression of sfGFP in CFPS systems (Fig. 5b). The effect of $10 \mathrm{mM}$ and $20 \mathrm{mM} \mathrm{Mg}{ }^{2+}$ on protein expression was similar in B. subtilis system. However, the expression of $20 \mathrm{mM} \mathrm{Mg}^{2+}$ in the other three systems was much lower than that in $10 \mathrm{mM} \mathrm{Mg}^{2+}$. It could be because the transcription and translation process of these three systems was more sensitive to the demand of $\mathrm{Mg}^{2+}$. The transcription and translation process of the $B$. subtilis system also kept working efficiently at $20 \mathrm{mM} \mathrm{Mg}{ }^{2+}$, but higher concentrations of $\mathrm{Mg}^{2+}$ led to a decrease in protein expression. E. coli, B. subtilis, C. glutamate and V. natriegens CFPS systems had the highest protein activity when the final concentration of 


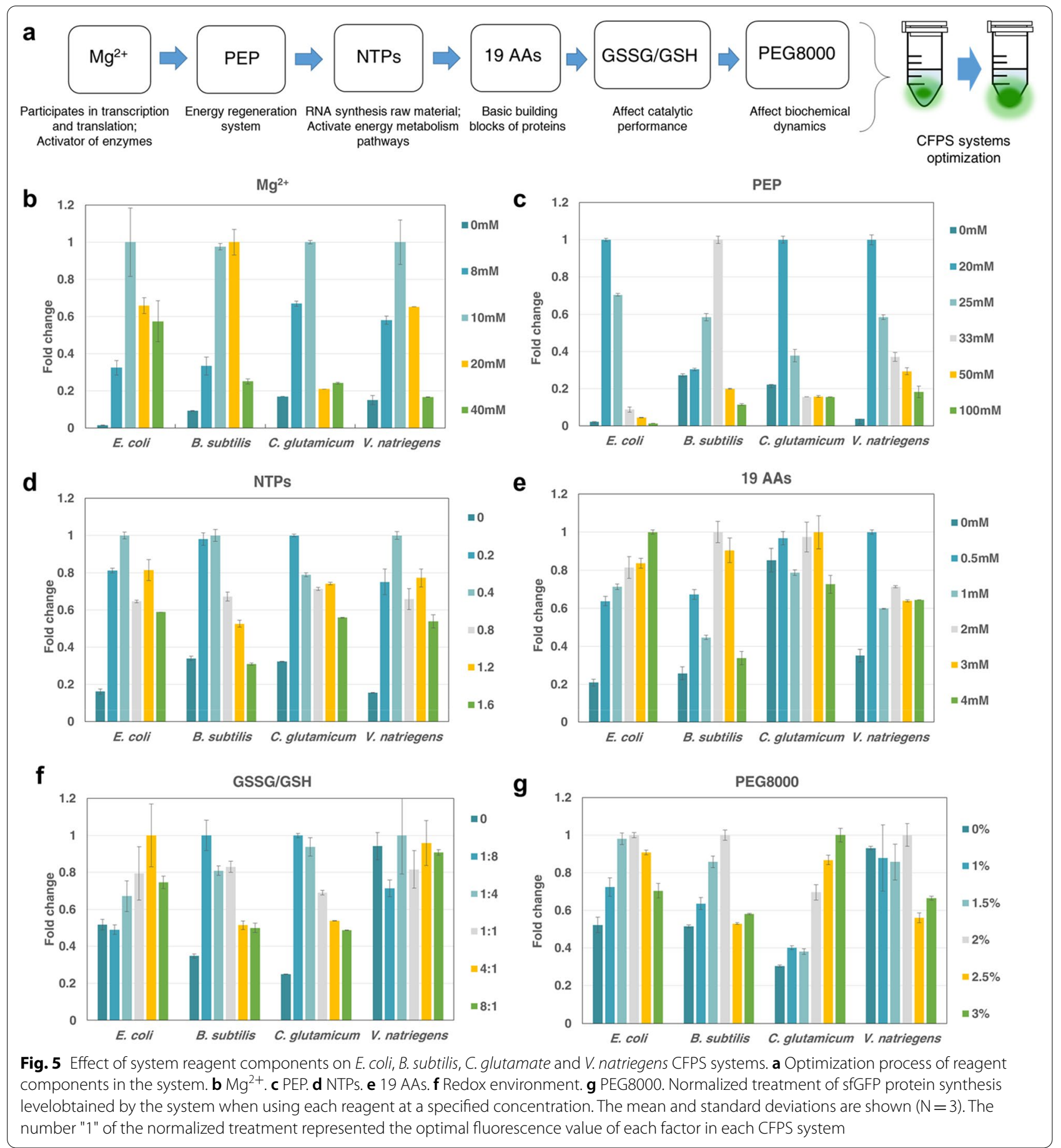

magnesium glutamate was $20 \mathrm{mM}, 10 \mathrm{mM}, 10 \mathrm{mM}$ and $10 \mathrm{mM}$, respectively.

In addition, providing sufficient energy for the transcription and translation processes in a CFPS system is also essential for efficient protein synthesis. Phosphoenolpyruvate (PEP) can be used as an energy regeneration system to activate the translation response in the CFPS system (Failmezger et al. 2018). It had a great influence on the protein expression of E. coli and $V$. natriegens CFPS system (Fig. 5c), and the maximum protein synthesis level differed by dozens of times. High concentration of PEP ( $33 \mathrm{mM})$ was more suitable for the protein expression of $B$. subtilis. Lower concentration of PEP $(20 \mathrm{mM})$ was more 
suitable for E. coli, C. glutamate and V. natriegens CFPS systems.

NTPs Mix is a hybrid system, including ATP, CTP, GTP, UTP, CoA, putrescine, spermine, NAD, tRNA and folic acid. NTPs are added to provide raw material for transcription. The addition of purified tRNA stimulates the translation process, and the addition of $\mathrm{NAD}^{+}$and CoA activates the pathway from pyruvate to acetylphosphate to stimulate energy metabolism. In this study, with the increase of NTPs content, the protein expression of the four systems showed a trend of increasing first, and too much NTPs was more detrimental to the protein expression of systems (Fig. 5d). The reason why excessive PEP and NTPs decreased protein expression in the systems might be that excessive phosphate was produced, which led to phosphate accumulation and was detrimental to protein synthesis. Compared with the three CFPS systems, it was found that the protein expression process of the B. subtilis CFPS system needed to provide more energy substances to support. E. coli, B. subtilis, C. glutamate and $V$. natriegens CFPS systems exhibited the highest protein expression when $0.4 \mu \mathrm{L}, 0.4 \mu \mathrm{L}, 0.2 \mu \mathrm{L}$ and $0.4 \mu \mathrm{L}$ NTPs were added to each reaction $(20 \mu \mathrm{L})$, respectively.

Amino acid is an essential substrate and key component of protein synthesis. In addition, certain amino acids are active participants in central metabolic pathways. According to the experimental results (Fig. 5e), for the $C$. glutamicum CFPS system, different amino acid concentrations had no significant effect on protein synthesis. The protein expression of $C$. glutamicum CFPS system was relatively high when the amino acid concentration was $3 \mathrm{mM}$. However, in E. coli, B. subtilis and V. natriegens CFPS systems, different concentrations of amino acids resulted in significant difference in the protein expression levels of the systems. Among them, the E. coli system required more amino acids to support the translation process. The protein expression levels of E. coli, $B$. subtilis and $V$. natriegens systems reached the peak at $4 \mathrm{mM}, 2 \mathrm{mM}$ and $0.5 \mathrm{mM}$ amino acids, respectively.

Next, the redox environment in the optimized reaction mixture was studied (Fig. 5f). The oxidation environment in the system is also a key factor affecting protein synthesis, because it can affect the catalytic performance of the system and also affect the formation of disulfide bonds in some proteins (Yin and Swartz 2004). The redox environment was regulated by the oxidized and reduced glutathione (GSSG and GSH). It was found that the addition of oxidizing reducing agent or the redox degree of the environment had little effect on the protein expression of the $V$. natriegens CFPS system. In addition, the oxidation environment was more conducive to protein synthesis for $E$. coli system, while the reductive environment was more preferred for B. subtilis and C. glutamicum systems.

Finally, the tested influence factor was molecular crowding degree. Molecular crowding, as a natural state of cells, affects the rate of diffusion and binding of molecules in the environment, which in turn affects protein synthesis (Tan et al. 2013). To restore the state of molecular crowding, a crowding agent, PEG8000 could be added to the CFPS system to simulate the degree of intracellular molecular crowding. It could be seen from the experimental data (Fig. $5 \mathrm{~g}$ ) that the molecular density in different cell-free environments still had a certain influence on protein expression. Among them, the addition of PEG8000 had little effect on the $V$. natriegens system, indicating that the molecular crowding degree of the $V$. natriegens system itself was also suitable for protein synthesis. The C. glutamicum system may be due to the low density of CFPS system compared with other systems, which required the addition of high concentration of PEG800 to maintain the crowding degree of the system, thus improving the macromolecular binding efficiency of the system. In addition, the high molecular density was not conducive to protein expression in $E$. coli, $B$. subtilis and $V$. natriegens systems. This might be due to the increased viscosity of the crowding agent, the high molecular density in the system, which increased the burden of the system and led to the decrease of protein expression efficiency. The protein synthesis efficiency of E. coli, B. subtilis and $V$. natriegens systems reached the highest, when 2\% PEG8000 was added, and the optimal PEG8000 concentration of C. glutamicum system was $3 \%$.

The correlation analysis results of different reagent components of four CFPS systems (Additional file 1: Table S5) showed that the influence degree of the six reagent components on the protein expression of four CFPS systems from large to small was as followed. $V$. natriegens: PEG8000, $\mathrm{Mg}^{2+}$, PEP, GSSG/GSH, NTPS, 19 AA; $B$. subtilis: NTPS, PEP, 19 AA, GSSG/GSH, $\mathrm{Mg}^{2+}$, PEG8000; C. glutamicum: PEG8000, PEP, $\mathrm{Mg}^{2+}, 19$ AA, GSSG/ GSH, NTPS; E. coli: 19 AA, GSSG/GSH, PEG8000, PEP, $\mathrm{Mg}^{2+}$, NTPS. By optimizing and comparing the influencing factors of different CFPS systems, the protein synthesis level of the system can be improved, and some factors with greater influence can be selected for targeted optimization, so as to eliminate the ineffective factors and improve the optimization efficiency.

The CFPS systems can quickly and conveniently add different concentrations of reagents to screen according to the needs of systems based on different hosts. This ability to adapt to the rapid optimization of each system is the outstanding advantage of the cell-free system. The protein yield of the system can be improved by directly optimizing the corresponding influencing factors. After a 
Table 2 Final protein expression levels of the four CFPS systems

\begin{tabular}{llcl}
\hline Bacterial species & $\begin{array}{l}\text { Unoptimized system } \\
\text { total protein } \mathbf{( m g / L )}\end{array}$ & $\begin{array}{c}\text { Optimized system } \\
\text { total protein } \mathbf{( m g / L )}\end{array}$ & Key factors of protein expression \\
\hline V. natriegens & $569.7 \pm 4.1$ & $725.3 \pm 22.6$ & Plasmid source, plasmid concentration, PEG8000, Mg ${ }^{2+}$, PEP \\
C. glutamicum & $287.2 \pm 25.5$ & $384.6 \pm 7$ & Plasmid source, plasmid concentration, codon, NTPs, PEP, 19 AA \\
B. subtilis & $306.1 \pm 9.6$ & $560.9 \pm 8.7$ & Plasmid source, plasmid concentration, PEG8000, PEP, Mg ${ }^{2+}$ \\
E. coli & $936.1 \pm 8.4$ & $1435.4 \pm 37$ & Plasmid source, plasmid concentration, codon, 19 AA, GSSG/GSH, PEG8000 \\
\hline
\end{tabular}

series of optimization work, the best components of the four CFPS systems were determined, as shown in Additional file 1: Table S3. The experimental results (Table 2) showed that the total protein synthesis of the sfGFP was improved in all four CFPS systems after optimization. The total sfGFP protein yield of the optimized $E$. coli, B. subtilis, C. glutamate and $V$. natriegens systems could reach $1435.4 \mathrm{mg} / \mathrm{L}, 560.9 \mathrm{mg} / \mathrm{L}, 384.6 \mathrm{mg} / \mathrm{L}$, and $725.3 \mathrm{mg} / \mathrm{L}$, respectively. By comparing the four optimized CFPS systems, it could be found that the expression levels of the constructed B. subtilis, C. glutamate and $V$. natriegens CFPS systems were still lower than that of the E. coli CFPS system, indicating that these three CFPS systems still need to be improved step by step.

\section{Expression of SARS-CoV-2 RBD protein and the effect of surfactants on protein solubility}

To better demonstrate that the CFPS systems could be a platform for therapeutic protein expression, the four optimized CFPS systems were used to express the RBD protein of SARS-CoV-2. SARS-CoV-2 is the most concerned virus at the moment because of its powerful infectivity and lethality (Wang et al. 2020; Zhai et al. 2020). S protein plays the most important role in the process of virus attachment, fusion and entry into host cells, and it acts on antibodies and is a target for the development of inhibitors and vaccines. The $\mathrm{S}$ protein of SARS-CoV-2 contains a receptor-binding domain (RBD) that specifically recognizes the receptor; thus $\mathrm{RBD}$ is a key target for antiviral compounds and antibodies (Fig. 6a) (Shang et al. 2020). Studies on the synthesis of RBD protein may contribute to the development of SARS-CoV-2 therapy. Therefore, the RBD-Foldon protein was selected as the target protein to be expressed in this study.

First, the expression of RBD-Foldon was proceeded to be tested by using the $V$. natriegens CFPS system. The results showed that RBD-Foldon could be successfully expressed, but the solubility of the protein was very low (Additional file 1: Fig. S1a). To improve protein solubility, two nonionic surfactants (Tween 20 and Brij-35) were used to test their effects on protein solubility in the CFPS systems. The nonionic surfactant interacts with the hydrophobic portion of the protein, thereby exposing hydrophilic groups present in both molecules (AguirreRamírez et al. 2021), which results in an increase in the hydrophilicity of the nonionic surfactant-protein complex, thereby reducing protein aggregation (Additional file 1: Fig. S2). The results were verified by protein western blotting, which showed that the addition of Tween 20 did not have a significant effect on protein solubility (Additional file 1: Fig. S1c). However, after the addition of Brij-35, the protein solubility increased significantly. Therefore, Brij-35 surfactant could effectively increase the solubility of protein (Additional file 1: Fig. S1b). Then, the RBD-Foldon was expressed in B. subtilis, C. glutamicum and E. coli CFPS systems (Additional file 1: Fig. S3). The three CFPS systems also added Brij-35 surfactant to test the protein solubility because of the better results of the $V$. natriegens system tested. It was clear that the RBDFoldon protein was successfully expressed in B. subtilis, C. glutamicum and E. coli CFPS systems, and the Brij-35 surfactant could significantly increase the protein solubility of the three CFPS systems. Finally, RBD-Foldon protein was expressed and quantified in four CFPS systems supplemented with Brij-35 (Additional file 1: Fig. S4).

To verify the functional activity of the proteins, the RBD-Foldon protein produced by the four CFPS systems were verified by ELISA assay (Fig. 6b). The Anti-His $_{6}$-Mouse Ab-HRP was titrated on the precoated, pre-blocked ACE2-Fc ELISA plate to determine the optimal dilution of the proteins to be used in the validation of the ELISA. From Additional file 1: Fig. S5, it could be seen that the color changed significantly after color development, which proved that the RBD-Foldon proteins produced by the four systems could bind to ACE2, and the binding rate of the samples was the highest at the original concentration. As can be seen from Fig. 5c, compared with the protein contents produced by the four CFPS systems (Additional file 1: Table S4), although the protein contents produced by $V$. natriegens and $C$. glutamicum CFPS systems were less than that of $E$. coli, these two CFPS systems had stronger protein production activity. Therefore, the RBD-Foldon proteins produced by E. coli, B. subtilis, C. glutamicum and V. 
a
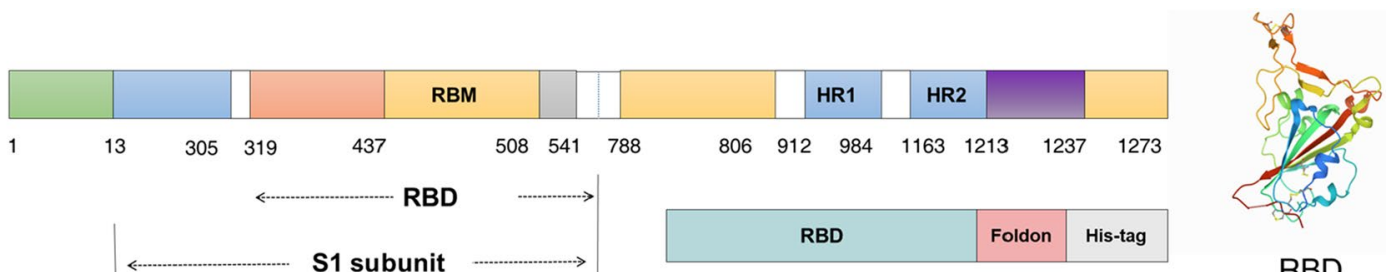

$\mathrm{RBD}$

b
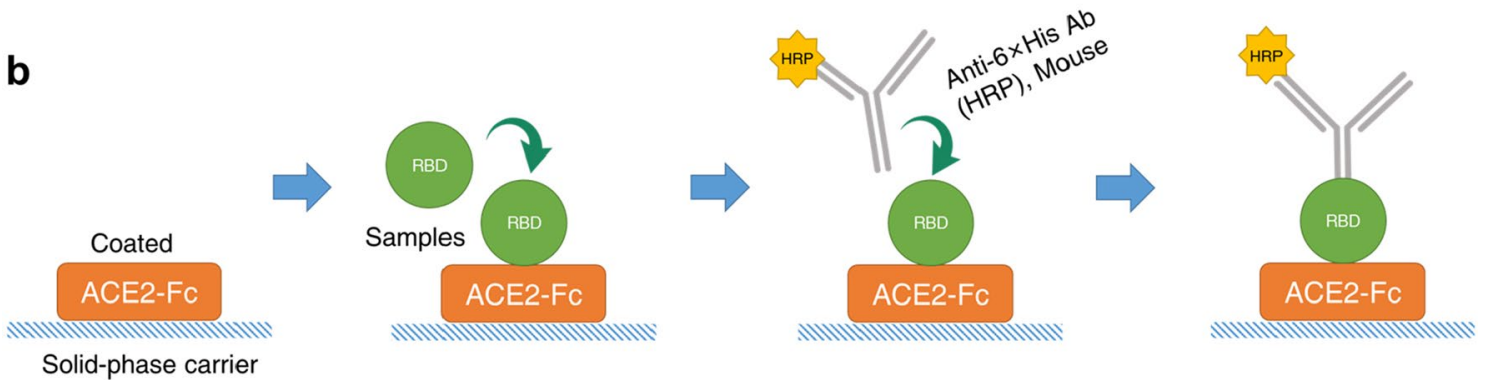

C

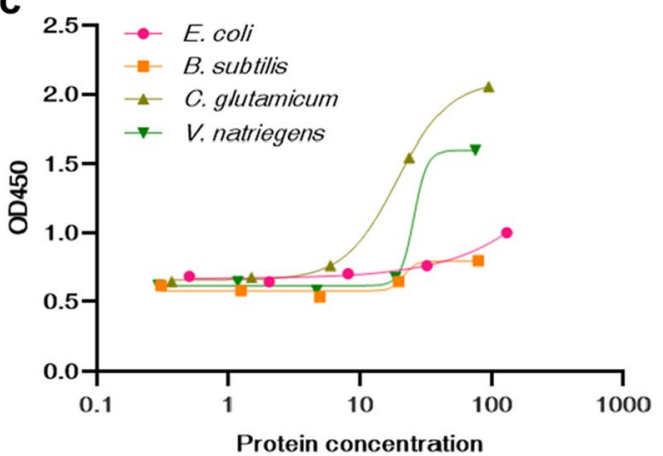

d

\begin{tabular}{cc}
\hline Samples & $\begin{array}{c}\text { Endotoxin concentration } \\
(\mathrm{EU} / \mathrm{mL})\end{array}$ \\
\hline E. coli & $325.5 \pm 15.0$ \\
B. subtilis & $0 \pm 0$ \\
C. glutamicum & $15.4 \pm 1.3$ \\
V. natriegens & $46.6 \pm 4.1$ \\
\hline
\end{tabular}

Fig. 6 The E. coli, B. subtilis, C. glutamicum and V. natriegens CFPS systems as a platform for pharmaceutical protein synthesis. a Protein structure diagrams and sequence design diagrams of RBD protein (PDB: 6VW1). b Schematic diagram of ELISA principle. $\mathbf{c}$ Absorbance of four system protein samples with different concentrations at $450 \mathrm{~nm}$. $\mathbf{d}$ Endotoxin detection of extracts in the four CFPS systems

natriegens CFPS systems could be verified by ELISA and were functionally active.

Next, the endotoxin of cell extracts from all four systems was tested. The results (Fig. 6d) showed that in the same volume of the four cell extracts, the endotoxin of B. subtilis, C. glutamicum, V. natriegens cell extract was significantly lower than that of E. coli. As we known, $B$. subtilis and C. glutamicum are Gram-positive bacteria and do not produce endotoxin. Part of the error might be due to the accumulation of lipopolysaccharide caused by microorganisms in the environment during the preparation process, which led to higher detection results. Therefore, the $V$. natriegens, C. glutamicum, B. subtilis CFPS systems were safer for the production of therapeutic proteins. Compared with the E. coli CFPS system, the $B$. subtilis, C. glutamicum and $V$. natriegens CFPS systems had more potential for the design and production of pharmaceutical proteins in the future.

\section{Conclusion}

$V$. natriegens, B. subtilis, C. glutamicum and E. coli are four well established model organisms with high potential and industrial value. In this study, E. coli, B. subtilis, $C$. glutamicum and $V$. natriegens CFPS systems were constructed, and their related process parameters were optimized. Through the comparison and analysis of the four CFPS systems, the advantages and important influencing factors of different systems were obtained. For example, B. subtilis and $V$. natriegens did not require codon optimization. The transcriptional and translation efficiency of $V$. natriegens, B. subtilis and C. glutamicum system were lower than that of $E$. coli. The endotoxin levels in the cell extracts of B. subtilis, C. glutamate and V. natriegens systems were much lower than that of $E$. coli. They not only expanded the potential options for in vitro protein production, but also increased the application range of the systems. 
According to the characteristics of different systems, a suitable system could be selected for applications. For example, all four CFPS systems were suitable for highthroughput screening of proteins. The endotoxin levels in the cell extracts of B. subtilis, C. glutamate and V. natriegens systems were much lower than that of $E$. coli, which could reduce the burden of downstream processing in the biopharmaceutical industry. Therefore, these three CFPS systems have greater potentials for the design and production of future drug proteins. However, due to the relatively low levels of protein synthesis in B. subtilis, $C$. glutamate and $V$. natriegens systems compared to $E$. coli system, some applications that require a higher protein yield, such as cell-free biosensors that require a stronger output signal, are still suitable for $E$. coli system.

The expression levels of B. subtilis, C. glutamate and $V$. natriegens CFPS systems were still lower than that of E. coli CFPS system, which might be due to inappropriate plasmid sources. Jurek Failmezger et al. (Failmezger, et al. 2017) found that plasmids with the same cellular background as the CFPS system were well expressed. In this study, E. coli-competent cells were used to extract plasmids, and pET-23a vector was used to synthesize the proteins, which might have certain limitations on the synthesis of different CFPS systems. Therefore, plasmids can be extracted from $V$. natriegens, $C$. glutamate and $B$. subtilis, respectively, and various expression vectors can be designed to further increase the expression of CFPS systems. In addition, studies on the metabolic pathways, gene circuits and diagnostic tools (Cho and Lu 2020; Lin et al. 2021; Lin et al. 2020a, b; Yang and Lu 2020) in the $E$. coli CFPS system can be tried in the other three systems, and a diversified CFPS platform can be developed further to expand the application scope of the CFPS systems.

\section{Materials and methods}

\section{Bacterial strains and plasmids}

The strains used in this study were Escherichia coli BL21 STAR(DE3), Bacillus subtilis 168, Corynebacterium glutamate MB001(DE3) and Vibrio natriegens Vmax (Additional file 1: Table S1). The sfGFP- $6 \times$ His plasmid, codon optimization plasmids and pET24a(+)-RBD-His plasmid were synthesized in GENEWIZ Company. All the plasmids used in this experiment were sequentially verified. More detailed information is shown in Additional file 1: Table S6.

\section{RBS library design}

Different RBS sequences were designed for each CFPS system to replace the original RBS sequence between the T7 promoter sequence and the initiation of sfGFP gene. RBS sequences were designed according to different hosts by the RBS library calculator (De Novo DNA: RBS Library Calculator) (Reis and Salis 2020; Salis et al. 2009). Because the range of translation initiation rates were very wide, so six RBS sequences (Table 1 ) were equably selected from the minimum to the maximum translation initiation rates. The designed RBS replaced the original RBS by site-specific mutagenesis. Then, the sequences were sent to the sequencing company to verify.

\section{RBD-Foldon protein design}

Foldon was added to the C-terminal end of the RBD designed in this study. The addition of Foldon allowed the formation of trimers after RBD expression, thus enhancing immunogenicity (Vogel et al. 2021).

\section{Cell culture}

To prepare the cell-free extracts (Gao et al. 2019; Jiang, et al. 2021), the cells of Bacillus subtilis 168, Corynebacterium glutamate MB001(DE3) and Vibrio natriegens Vmax were resurrected from glycerin to the antibioticfree LB plate. After inoculation, the colonies were inoculated in $5 \mathrm{~mL} \mathrm{LB}$ medium (first grade seed solution) and incubated overnight at $30{ }^{\circ} \mathrm{C}(200 \mathrm{rpm})$. Escherichia coli BL21 star (DE3) was cultured in ampicillin medium and at $37^{\circ} \mathrm{C}$. The culture was diluted (1:20), added into a bottle containing $200 \mathrm{~mL} 2 \times$ YTP medium (secondary seed solution), and shaken at $30{ }^{\circ} \mathrm{C} / 37{ }^{\circ} \mathrm{C}(200 \mathrm{rpm})$ to $\mathrm{OD}$ at $0.8 \sim 1$. Then the culture was diluted (1:20) and added into a bottle containing $2 \mathrm{~L} 2 \times$ YTP medium (tertiary seed solution). After shaking at $30{ }^{\circ} \mathrm{C} / 37{ }^{\circ} \mathrm{C}(200 \mathrm{rpm})$ until the end of the logarithmic growth period, the cells were harvested. By comparing the growth rate of the four bacteria, E.coli and $V$. natriegens could reach the collecting stage faster. The bacterial solution was centrifuged at $8000 \mathrm{rpm}$, at $4{ }^{\circ} \mathrm{C}$, for $30 \mathrm{~min}$. The Bacillus subtilis produced spores that made it difficult to centrifuge, so that the centrifugation speed could be slightly increased. For the same volume of culture, there were much fewer bacteria in B. subtilis and C. glutamate than that in $E$. coli and $V$. natriegens. The bacteria were resuspended with crushing buffer S30A (14 mM Mg-glutamate, $60 \mathrm{mM}$ K-glutamate, $50 \mathrm{mM}$ Tris, $\mathrm{pH}$ 7.7) and transferred into a $50-\mathrm{mL}$ pre-weighing Falcon tube. The suspension was centrifuged at $8000 \mathrm{rpm}$ at $4{ }^{\circ} \mathrm{C}$ for $10 \mathrm{~min}$.

\section{Extract preparation}

Added $1 \mathrm{~mL}$ of S30A buffer for each gram of bacteria body, suspended again, and waited for use. An appropriate amount of ice water mixture was added into the high-pressure crushing apparatus to create a low-temperature environment and prevent overheating in the crushing process, which could affect the activity of cell 
extracts. Bacteria were crushed 2-3 times with a highpressure crushing apparatus $(15,000 \mathrm{~Pa})$. The broken samples were centrifuged at $10,000 \mathrm{rpm}$ at $4{ }^{\circ} \mathrm{C}, 30 \mathrm{~min}$. After centrifugation, the supernatant was transferred to the new BD tube, and $3 \mu \mathrm{l}$ of $1 \mathrm{M}$ DTT were added to each $1 \mathrm{~mL}$ solution. Then wrapped in foil, placed in a shaker at $37{ }^{\circ} \mathrm{C}$ away from light, and incubated at $120 \mathrm{rpm}, 80 \mathrm{~min}$. After incubation, the samples were centrifuged at $10,000 \mathrm{rpm}, 4{ }^{\circ} \mathrm{C}, 30 \mathrm{~min}$, and the supernatant was retained. The supernatant was added to the dialysis bag of MWCO 6-8 kDa, and the dialysis buffer S30B (14 mM Mg-glutamate, $60 \mathrm{mM} \mathrm{K}$-glutamate, $5 \mathrm{mM}$ Tris, $\mathrm{pH}$ 8.2) was used for dialysis at $4{ }^{\circ} \mathrm{C}, 4 \mathrm{~h}$. The liquid in the dialysis bag was transferred to the $\mathrm{BD}$ tube, centrifuged at $10,000 \mathrm{rpm}, 4{ }^{\circ} \mathrm{C}, 30 \mathrm{~min}$, and the supernatant was retained. The supernatant was separated on ice, and stored in the refrigerator at $-80{ }^{\circ} \mathrm{C}$ after rapid freezing of liquid nitrogen until used.

\section{Standard cell-free protein synthesis reaction}

The standard CFPS reaction was conducted in a $1.5 \mathrm{~mL}$ EP (Eppendorf) tube at a volume of $20 \mu \mathrm{L}$, incubated overnight (about $13 \mathrm{~h}$ ) at $30{ }^{\circ} \mathrm{C}$. Then the protein synthesis level was detected with a microplate analyzer. The standard reaction mixture consists of the following components (Gao et al. 2019; Jiang et al. 2021): $300 \mathrm{ng} / \mathrm{mL}$ plasmid DNA, $175 \mathrm{mM}$ potassium glutamate, $10 \mathrm{mM}$ ammonium glutamate, $2.7 \mathrm{mM}$ potassium oxalate, $100 \mathrm{mM}$ magnesium glutamate, $2.5 \%$ PEG8000, 1 M PEP solution, $50 \mathrm{mM} 19$ amino acids, $25 \times$ NTP Mix $(1 \mathrm{mM}$ puttamine, $1.5 \mathrm{mM}$ spermidine, $0.33 \mathrm{mM}$ NAD, $1.2 \mathrm{mM}$ ATP, $0.86 \mathrm{mM}$ CTP, $0.86 \mathrm{mM}$ GTP, $0.86 \mathrm{mM}$ UTP, $0.27 \mathrm{mM} \mathrm{CoA}, 170 \mathrm{~g} / \mathrm{mL}$ tRNA) and $\mathrm{ddH}_{2} \mathrm{O}$.

\section{ELISA}

Each ELISA plate was covered with $2 \mu \mathrm{g} / \mathrm{mL}$ antigen (diluted with coated solution) $50 \mu \mathrm{L}$, and incubated overnight at $4{ }^{\circ} \mathrm{C}$ (sealed film). The next day, each well was washed with $200 \mu \mathrm{L}$ PBS 3 times. Each well was sealed with blocking solution $200 \mu \mathrm{L}$ at room temperature for $1 \mathrm{~h}$. After sealing, each well was washed with $200 \mu \mathrm{L}$ PBS 3 times. The sample was diluted with blocking solution (gradient dilution), $50 \mu \mathrm{L}$ was added to each well (do not add to the wall), and incubated at room temperature for $3 \mathrm{~h}$ (seal the film). Then washed with $200 \mu \mathrm{L}$ PBS 3 times per well. Added $0.2 \mu \mathrm{g} / \mathrm{mL}$ His Ab-HRP antibody $50 \mu \mathrm{L}$ to each well (diluted with blocking solution), and incubated at room temperature for $1 \mathrm{~h}$ (sealed film). Washed with $200 \mu \mathrm{L}$ PBS 3 times per well. Added $100 \mu \mathrm{L}$ TMB solution to each well, waited for color change (the color turned blue if there is antigen-antibody binding). After the color remained the same, $100 \mu \mathrm{L}$ stop solution (2 $\mathrm{M}$ sulfuric acid) was added to each well to terminate the solution, and then read at $450 \mathrm{~nm}$ with a microplate meter. First, the commercial standard RBD protein was tested by ELISA, which proved that RBD protein could be successfully bound to ACE2 protein. Then, the RBD proteins produced by the four CFPS systems were validated by ELISA.

\section{Gene expression analysis}

Fluorescence output representing gene expression level was measured online in an infinite M200PRO (TECAN) by fluorescence (excitation filter $485 \mathrm{~nm}$, emission $525 \mathrm{~nm}$ ). When the cell-free reaction was completed, $10 \mu \mathrm{L}$ sample and $190 \mu \mathrm{L}$ water was mixed and read in a black, flat-bottomed 96-well analysis plate (CORNING). Before each reading cycle, the plate was shaken.

\section{Endotoxin analysis}

The endotoxin of extract samples was detected using the bacterial endotoxin (ET) ELISA Kit (Shanghai mlbio Co.) and quantified according to the standard curve (Additional file 1: Fig. S6).

\section{Protein quantification}

Western blot analysis was performed on the sample protein and standard gradient protein. The standard curve established by quantitative standard sfGFP protein sample was used, and the gray value was converted to protein concentration calculated by ImageJ software.

\section{Abbreviations}

CFPS: Cell-free protein synthesis; RBS: Ribosomal binding site; sfGFP: Superfolder green fluorescent protein; PEP: Phosphoenolpyruvate; RBD: Receptorbinding domain; ELISA: Enzyme-linked immunosorbent assay.

\section{Supplementary Information}

The online version contains supplementary material available at https://doi. org/10.1186/s40643-021-00413-2.

Additional file 1: Fig. S1. Western blot analysis of the RBD-Foldon in the $V$. natriegens CFPS system. a. RBD-Foldon expression of the original $V$. natriegens system; $b$. RBD-Foldon expression of $V$. natriegens system after add the surfactant Brij-35; c. RBD-Foldon expression of the $V$. natriegens system after add the surfactant Tween 20. Fig. S2. Schematic diagram of the effect of surfactants on protein structure. Fig. S3. Western blot analysis of RBD-Foldon in the C. glutamicum, B. subtilis and E. coli CFPS systems. Fig. S4. Western blot and quantitative analysis of RBD-Foldon in E. coli, B. subtilis, C. glutamicum and V. natriegens CFPS systems. Fig. S5. Color change of four CFPS samples after TMB development and after termination of color development. Fig. S6. The standard curve of endotoxin. Fig. S7. The map of pET23a-sfGFP- $6 \times$ His. Fig. S8. The map of pET24a(+)-RBD-His. Fig. S8. Flow chart of experimental design. Table S1. The strains in this study. Table S2. The concentrations of components in original reference CFPS systems. Table S3. Addition gradient of CFPS system components. 
Table S4. Optimum conditions in the V. natriegens, C. glutamicum, B. subtilis and E. coli CFPS expression systems. Table S5. The significance analysis of different reagent components in four CFPS system.

\section{Acknowledgements}

Not applicable.

\section{Authors' contributions}

LZ, XL and TW: conceptualization, methodology, investigation, data curation, formal analysis, writing-original draft preparation, and writing-reviewing and editing. WG: supervising, and writing-reviewing and editing. YL: supervision, project administration, funding acquisition, and writing-reviewing and editing. The paper was reviewed and approved by all authors prior to submission for peer review. All authors read and approved the final manuscript.

\section{Funding}

This work was supported by the National Key R\&D Program of China (2018YFA0901700), National Natural Science Foundation of China (21878173), Beijing Natural Science Foundation (2192023), and Laboratory Innovation Fund of Tsinghua University.

\section{Availability of data and materials}

All data generated or analyzed during this study are included in this published article.

\section{Declarations}

\section{Ethics approval and consent to participate}

Not applicable.

\section{Consent for publication}

Not applicable.

\section{Competing interests}

The authors declare that they have no competing interests.

Received: 15 May 2021 Accepted: 29 June 2021

Published online: 06 July 2021

\section{References}

Adiga R, Al-adhami M, Andar A et al (2018) Point-of-care production of therapeutic proteins of good-manufacturing-practice quality. Nat Biomed Eng 2:675-686

Aguirre-Ramírez M, Silva-Jiménez H, Banat IM et al (2021) Surfactants: physicochemical interactions with biological macromolecules. Biotech Lett 43:523-535

Becker W, Wimberger F, Zangger K (2019) Vibrio natriegens: an alternative expression system for the high-yield production of isotopically labeled proteins. Biochemistry 58:2799-2803

Carlson ED, Gan R, Hodgman CE et al (2012) Cell-free protein synthesis: applications come of age. Biotechnol Adv 30:1185-1194

Carroll AC, Wong A (2018) Plasmid persistence: costs, benefits, and the plasmid paradox. Can J Microbiol 64:293-304

Casali N (2003) Escherichia coli host strains. Methods in Mol Biol 235:27-48

Chappell J, Jensen K, Freemont PS (2013) Validation of an entirely in vitro approach for rapid prototyping of DNA regulatory elements for synthetic biology. Nucleic Acids Res 41:3471-3481

Cho E, Lu Y (2020) Compartmentalizing cell-free systems: toward creating lifelike artificial cells and beyond. ACS Synth Biol 9:2881-2901

Dalia TN, Hayes CA, Stolyar S et al (2017) Multiplex genome editing by natural transformation (MuGENT) for synthetic biology in Vibrio natriegens. ACS Synth Biol 6:1650-1655

Des Soye BJ, Davidson SR, Weinstock MT et al (2018) Establishing a high-yielding cell-free protein synthesis platform derived from Vibrio natriegens. ACS Synth Biol 7:2245-2255
Failmezger J, Rauter M, Nitschel R et al (2017) Cell-free protein synthesis from non-growing, stressed Escherichia coli. Sci Rep 7:1-10

Failmezger J, Scholz S, Blombach B et al (2018) Cell-free protein synthesis from fast-growing Vibrio natriegens. Front Microbiol 9:1146

Fernández-Llamosas H, Castro L, Blázquez ML et al (2017) Speeding up bioproduction of selenium nanoparticles by using Vibrio natriegens as microbial factory. Sci Rep 7:1-9

Gao W, Bu N, Lu Y (2019) Efficient incorporation of unnatural amino acids into proteins with a robust cell-free system. Methods Protocols 2:16

Gregorio NE, Levine MZ, Oza JP (2019) A user's guide to cell-free protein synthesis. Methods Protocols 2:4

Guan C, Cui W, Cheng J et al (2016) Development of an efficient autoinducible expression system by promoter engineering in Bacillus subtilis. Microb Cell Fact 15:66

Hodgman CE, Jewett MC (2012) Cell-free synthetic biology: thinking outside the cell. Metab Eng 14:261-269

Jeong D-E, Park S-H, Pan J-G et al (2014) Genome engineering using a synthetic gene circuit in Bacillus subtilis. Nucleic Acids Res 43:e42-e42

Jiang N, Ding X, Lu Y (2021) Development of a robust Escherichia colibased cell-free protein synthesis application platform. Biochem Eng J 165:107830

Karim AS, Jewett MC (2016) A cell-free framework for rapid biosynthetic pathway prototyping and enzyme discovery. Metab Eng 36:116-126

Kelwick R, MacDonald JT, Webb AJ et al (2014) Developments in the tools and methodologies of synthetic biology. Front Bioeng Biotechnol 2:60

Kelwick R, Webb AJ, MacDonald JT et al (2016) Development of a Bacillus subtilis cell-free transcription-translation system for prototyping regulatory elements. Metab Eng 38:370-381

Levine MZ, Gregorio NE, Jewett MC et al (2019) Escherichia coli-based cell-free protein synthesis: protocols for a robust, flexible, and accessible platform technology. J vis Exp. https://doi.org/10.3791/58882

Li T, Ye J, Shen R et al (2016) Semirational approach for ultrahigh poly(3hydroxybutyrate) accumulation in Escherichia coli by combining one-step library construction and high-throughput screening. ACS Synth Biol 5:1308-1317

Li J, Wang H, Kwon YC et al (2017) Establishing a high yielding streptomyces-based cell-free protein synthesis system. Biotechnol Bioeng 114:1343-1353

Lin XM, Li YT, Li ZX et al (2020a) Portable environment-signal detection biosensors with cell-free synthetic biosystems. RSC Adv 10:39261-39265

Lin XM, Zhou C, Zhu S et al (2020b) O(2)-tuned protein synthesis machinery in Escherichia coli-based cell-free system. Front Bioeng Biotechnol 8:312

Lin XM, Li YT, Li ZX et al (2021) A robust Escherichia coli cell-free expression toolbox driven by sigma factors. Biochem Eng J 171:108031

Lu Y (2017) Cell-free synthetic biology: engineering in an open world. Synth Syst Biotechnol 2:23-27

Miyakoshi M, Nishida H, Shintani M et al (2009) High-resolution mapping of plasmid transcriptomes in different host bacteria. BMC Genomics 10:12

Moore SJ, Lai HE, Needham H et al (2017) Streptomyces venezuelae TX-TL-a next generation cell-free synthetic biology tool. Biotechnol J 12:1600678

Moore SJ, MacDonald JT, Wienecke S et al (2018) Rapid acquisition and model-based analysis of cell-free transcription-translation reactions from nonmodel bacteria. Proc Natl Acad Sci USA 115:E4340-e4349

Pardee K, Green AA, Takahashi MK et al (2016) Rapid, low-cost detection of zika virus using programmable biomolecular components. Cell 165:1255-1266

Phillips TA, VanBogelen RA, Neidhardt FC (1984) lon gene product of Escherichia coli is a heat-shock protein. J Bacteriol 159:283-287

Reis AC, Salis HM (2020) An automated model test system for systematic development and improvement of gene expression models. ACS Synth Biol 9:3145-3156

Russell DW, Zinder ND (1987) Hemimethylation prevents DNA replication in $E$. coli. Cell 50:1071-1079

Salis HM (2011) The ribosome binding site calculator. Methods Enzymol 498:19-42

Salis HM, Mirsky EA, Voigt CA (2009) Automated design of synthetic ribosome binding sites to control protein expression. Nat Biotechnol 27:946-950

Sarah G, Vincent S, Chang HJ et al (2016) A part toolbox to tune genetic expression in Bacillus subtilis. Nucleic Acids Res 44:7495-7508 
Schoborg JA, Hershewe J, Stark JC et al (2018) A cell-free platform for rapid synthesis and testing of active oligosaccharyltransferases. Biotechnol Bioeng 115:739-750

Shang J, Ye G, Shi K et al (2020) Structural basis of receptor recognition by SARS-CoV-2. Nature 581:221-224

Shi F, Luan M, Li Y (2018) Ribosomal binding site sequences and promoters for expressing glutamate decarboxylase and producing $\gamma$-aminobutyrate in Corynebacterium glutamicum. AMB Express 8:61

Smith KM, Cho KM, Liao JC (2010) Engineering Corynebacterium glutamicum for isobutanol production. Appl Microbiol Biotechnol 87:1045-1055

Smith MT, Berkheimer SD, Werner CJ et al (2014) Lyophilized Escherichia coli-based cell-free systems for robust, high-density, long-term storage. Biotechniques 56:186-193

Stech M, Kubick S (2015) Cell-free synthesis meets antibody production: a review. Antibodies 4:12-33

Sullivan CJ, Pendleton ED, Sasmor HH et al (2016) A cell-free expression and purification process for rapid production of protein biologics. Biotechnol J 11:238-248

Sun $\mathrm{H}$, Zhao D, Xiong B et al (2016) Engineering Corynebacterium glutamicum for violacein hyper production. Microb Cell Fact 15:148

Tan C, Saurabh S, Bruchez MP et al (2013) Molecular crowding shapes gene expression in synthetic cellular nanosystems. Nat Nanotechnol 8:602-608

Tschirhart T, Shukla V, Kelly EE et al (2019) Synthetic biology tools for the fastgrowing marine bacterium Vibrio natriegens. ACS Synth Biol 8:2069-2079

Vogel AB, Kanevsky I, Che $Y$ et al (2021) BNT162b vaccines protect rhesus macaques from SARS-CoV-2. Nature 592:283-289

Wang H, Li J, Jewett MC (2018) Development of a Pseudomonas putida cellfree protein synthesis platform for rapid screening of gene regulatory elements. Synth Biol 3:ysy003
Wang MY, Zhao R, Gao LJ et al (2020) SARS-CoV-2: structure, biology, and structure-based therapeutics development. Front Cell Infect Microbiol 10:587269

Weinstock MT, Hesek ED, Wilson CM et al (2016) Vibrio natriegens as a fastgrowing host for molecular biology. Nat Methods 13:849

Wiegand DJ, Lee HH, Ostrov N et al (2018) Establishing a cell-free Vibrio natriegens expression system. ACS Synth Biol 7:2475-2479

Yang JZ, Lu Y (2020) Physical stimuli-responsive cell-free protein synthesis. Synth Syst Biotechnol 5:363-368

Yin G, Swartz JR (2004) Enhancing multiple disulfide bonded protein folding in a cell-free system. Biotechnol Bioeng 86:188-195

Zemella A, Thoring L, Hoffmeister C et al (2015) Cell-free protein synthesis: pros and cons of prokaryotic and eukaryotic systems. ChemBioChem 16:2420-2431

Zhai P, Ding Y, Wu X et al (2020) The epidemiology, diagnosis and treatment of COVID-19. Int J Antimicrob Agents 55:105955

Zhang P, Feng H, Yang J et al (2019) Detection of inorganic ions and organic molecules with cell-free biosensing systems. J Biotechnol 300:78-86

Zhang L, Guo W, Lu Y (2020) Advances in cell-free biosensors: principle, mechanism, and applications. Biotechnol J 15:e2000187

\section{Publisher's Note}

Springer Nature remains neutral with regard to jurisdictional claims in published maps and institutional affiliations.

\section{Submit your manuscript to a SpringerOpen ${ }^{\circ}$ journal and benefit from:}

- Convenient online submission

- Rigorous peer review

- Open access: articles freely available online

- High visibility within the field

- Retaining the copyright to your article

Submit your next manuscript at $\boldsymbol{\nabla}$ springeropen.com 